\title{
Being an African American Male in Birth Work
}

\author{
William Moore, CPE
}

\begin{abstract}
As an African American male working in public health, the author has few peers in the field who can related to his experiences from a gender and race standpoint, and even fewer in his work as a doula and lactation educator. His work and experiences as a trail blazer in this field have involved a lot of emotional labor, but have been a blessing and a joy as well as providing him with a unique lens into the world of birth work and how nuances at the intersection of gender and race affect his peers.
\end{abstract}

Keywords: doula; lactation; consultant; male; African American; birth work

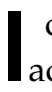
considered starting this article like one of those action movies, with a still image of me sitting in a precarious position, a look of surprise on my face, with the quote, "I bet you're wondering how I got here." If you'd asked me 3 or 4 years ago if I would be where I am today, doing what I'm doing and enjoying it as much as I am, that indeed would have been a huge surprise. But it isn't just a surprise to me-It's a surprise to many folks I encounter both personally and professionally. It has to do with who and what I am. I'm an ex-football player who works in Public Health. But it doesn't stop there; not only is it uncommon to find many men in Public Health, it's uncommon to find many Black men in Public Health. Not only am I an ex-football player in Public Health, and a Black manI'm a doula and lactation educator. And yes, you read that correctly. It's one of the occupations I picked up in Public Health, and it's the reason I'm writing this article.

My road to this position is something I'll get to, but my focus will most importantly be on my experiences since I got my certification over a year ago, which would open a door to a passion I never knew I had, and a connection to a cultural practice I never knew the significance of. As a county Public Health worker and a facilitator of a men's outreach group called Club Dad, I regularly attend a monthly meeting of the Birth Equity Community Council (BECC), which addresses child and maternal health disparities in Ramsey County, Minnesota, by inviting community members and professionals from all spheres in the
Twin Cities of Minneapolis and St. Paul-health care, social services, or any other direct service providersto put their minds together and brainstorm innovative goals and steps to solve a very real issue of disparities. What I'm referring to is that Black babies are twice as likely to die before the age of 1 year as White babies (Garcia-Navarro, NPR, 2018) (Minnesota Department of Health, 2018), and that Black women are 243\% more likely than White women to die as a result of pregnancy- or childbirth-related causes, according to the Centers for Disease Control and Prevention (Martin \& Montagne, 2017).

At a BECC meeting, someone proposed using grant money to collaborate with the Cultural Wellness Center (a well-respected community institution in Minneapolis) and the Integrated Care for High Risk Pregnancies (ICHRP) initiative of the Wilder Foundation, to train men to become licensed doulas and lactation educators; although there were many resources out there for moms and single women, there was a dire need for parenting resources for men. The strategy was that by training men to become doulas and lactation educators, not only could they support women, but their main goal would be to teach men in the community about the birth process and prepare them to be a support system for their significant others as well as other expectant mothers in the community. These trained men would be a resource on the birth process for men in the community who are expecting children.

Any new initiative or opportunity needs someone willing to take advantage of it, and I, along with one 


\begin{tabular}{l} 
In my training I learned about the \\
historical role and significance of \\
birth work in the Black community, \\
and that turned my desire to give \\
back to my community in an \\
innovative way into a feeling of \\
cultural responsibility that I was \\
happy to carry on my shoulders. \\
\hline
\end{tabular}

other individual, was willing to do so. Through my training I learned so much about the historical role and significance of birth work in the Black community, and that turned my desire to give back to my community in an innovative way into a feeling of cultural responsibility that I was happy to carry on my shoulders.

The experience itself has been quite an adventure. When people find out what I do, I'm almost always met with a look of shock or surprise, and then typically with a response that is one of two extremes: either they are happy and think that it's amazing and much needed for men to take part in birth work, or the opposite. That second group don't know how to feel about it. They question why I'm in "women's work"; they question my credentials; in one sad scenario another professional asked me if I actually knew what a doula was. Some people ask me if the parents and families are the most taken back or surprised when I'm introduced to them as a birth worker. It's actually the families who I've had the least amount of skepticism from. In my experience, the families take all of about 5 seconds to give a quizzical look, and then move on, because all they truly want is help. It's other professionals who often ask to see credentials, who try to test me on what I know about birth work, or question how long I've been in the field.

It used to really upset me until one day I sat by myself trying to make sense of it all, and put it into perspective. You see, even though I face discrimination every day in many different aspects of my life as a Black man, I'm still a man living in a male-dominated world. When I thought about the work I'm doing, seemingly blazing a trail as a man (one of the first two men in Minnesota history to be a certified doula and lactation educator) in a field that is predominantly female, in some respects I'm not experiencing anything new. What I experience with the puzzled looks, the doubt from some professionals, the posturing, and the tokenizing, is something many women have to endure when entering a field of work that's dominated by men. When I looked at it that way, it stopped being as annoying, and turned into something that I was more apt to face head-on as the competitive individual I am.

When it comes to working with men, women, and families, my experiences have been almost always positive. There have been very few questions about how I got into birth work, no questions about my credentials except for the occasional curiosity from both men and women about how they might get involved in birth work, and, most importantly, the questions I get are about how I can best help them as individuals, and as a family, bring their child into this world and lay the strongest foundation possible for successful co-parenting.

I have not once been told that I cannot work with a family, but when working with families I do have contracts that specifically articulate or ask for permission from both the mother and her partner to work with the family, because I want the entire family to feel included in all decision-making, and for everyone to be aware of what my work entails. I never work with a mother alone, and always have someone else (a partner or nurse) in the room with us. This is because of the gender difference, in case you were wondering: It's simply a way to make the family feel comfortable and protected (and myself as well). It's an act of professionalism that I think families appreciate, and it is another way to establish trust, letting families know that I'm willing to do whatever it takes to give them the best care, feel valued, and trust that my work is being done in good faith. When it comes to working with just fathers or with families as a group, I don't require such precautions. As a man it's important for me to take such precautions because the work sometimes requires mothers to share very personal things about themselves, and I want us all to have certain built-in boundaries to be able to count on. This is also why I need and desire to make sure all families and partners are involved in the process. For some men, having another man be involved in close spaces, seeing their significant other in a very intimate way (a way in which they may have been the only other person to see her in), is a big deal. If I don't take this into account, it can become a barrier, showing a lack of respect for one or both partners' comfort level and boundaries. Having something that both partners are heavily involved in and have an equal say in defuses a situation before it starts.

In my work with other professionals, there has been a much wider range of experiences. First the good: I've gotten many positive responses from other 
birth workers, Public Health workers, and direct service providers. There have been many who share a genuine excitement and gratitude toward me for being a man involved in birth work, bringing awareness to other men about the importance of male involvement in birth work and breastfeeding. And it's very important, especially when one of the main reasons many women give up on breastfeeding is because of lack of support (Centers for Disease Control and Prevention, 2019). Who better to support a woman through this than the father of the baby or the partner? That's one of the things that's so important about my work.

I get a lot of inquisitive responses from other professionals as well-folks who are eager to learn about my journey, methods, and goals in this space. I meet many professionals who are eager to collaborate, network, and spread the word about the unique resources or perspective that I provide as a male in birth work. Those experiences bring me a lot of joy and excitement. Besides the positivity that I get from helping a new family, or seeing the light bulb go on in a man who begins to understand his importance in the birth process, it's one of the most rewarding parts of the work.

With the good comes the bad as well. There's also tokenism that I experience as a male in birth work. There's a need or expectation, by some individuals or institutions, to include me in anything and everything, not because of my ability, but because they can check the diversity or inclusion box, much like the tokenism I experience as an African American in many spaces. I feel this tokenism both ways: because of my skin color and my gender. As bothersome as it can be, I handle these situations on a case-by-case basis. Sometimes I work in the environment and collaborate anyway, because I see that the need for my presence is more important than my need to back away. In other situations I've chosen to back away and not take part, because the benefit did not outweigh the emotional labor that I had to carry or endure in that particular instance. Some days I'm up for the battle, and some days I've got no time for the hassle. It's hard enough as an African American to wake up every day and go out into a world that does its absolute best to tell you that it hates you because of what you look like, and to work within or around systems that in many cases are designed to kill you for what you look like.

The stress and the emotional load are a lot. There are days where I literally get up in the morning, look in the mirror, and give myself a pep talk as if I'm getting ready to compete in a game. Except the stakes are not wins or losses, but my sanity. In extreme cases for some of my brothers and sisters out in the world, it's life or death. It's the reason why I've told some folks that my work isn't pressure. I don't feel peer pressure, and meeting someone's family or any other superficial deed or experience isn't pressure. Being Black in America is enough pressure. It's pressure that you're born with and feel even though you can't articulate it until you get older and further understand racial relations and the way they fall within the social construct in America. When I deal with this on a constant basis, some days, every now and then I don't really have the capacity to be someone's token Black male to make them feel comfortable.

There are those who doubt my ability, who question my credentials and think they're being sly when asking me a litany of questions that are disguised as curiosity but are really a veiled attempt to give me a verbal exam about the birth process, my duties and responsibilities as a doula, and my overall competency in birth work. I've addressed this several ways. Sometimes I simply humor them by answering their questions and peppering them with my own. Other times I call them out directly, asking them why it's so hard to believe that I can do my job, and on every occasion the response is, “Oh, I'm sorry, I didn't mean to offend you. I was just curious." But both of us know that they don't quiz their other colleagues that way, and I'm experienced enough through life as a Black man excelling and being in spaces that folks don't expect me to be in, to know the difference between real curiosity and condescending doubt. There are moments of disbelief and wonder about why I want to be involved in "women's work" - when I'm told that "I don't fit the profile" of a doula (because you know, when you think doula, you think middle-aged or hipster White woman).

I know some of them question my ability to do the work because I'm a man, and the thought of women being comfortable enough exposing private parts of the body to me is hard for them to fathom. Although they may not see it as offensive, I remind them how they would feel if I asked them about why they took part in any activity that wasn't deemed to be stereotypically female. I also remind them that birth work is family work. Therefore caring for or taking care of

I meet many professionals who
are eager to collaborate, network,
and spread the word about the
unique resources or perspective
that I provide as a male in birth
work.




\begin{tabular}{c}
\hline There are moments of disbelief \\
and wonder about why I want to \\
be involved in "women's \\
work" - when I'm told that "I don't \\
fit the profile" of a doula (because \\
you know, when you think doula, \\
you think middle-aged or hipster \\
White woman).
\end{tabular}

your family is not work relegated to women. It's been a real lesson for me in how preconceived gender roles doesn't just infect the minds of men, but are perpetuated and enforced by women as well.

Another form of pushback has come from other doulas. These are women who take issue with a man who involves himself with or feels comfortable in a "women's world" or field. The snide remarks and outright tone that was given to me by one woman during a group presentation was palpable. I had to call her out directly but respectfully, and let her know that the lack of respect or support she's gotten as a doula is not a reflection of me or my involvement in the work, and that the progress I've made in the field has been by my effort. She back-pedaled some when she saw that I wasn't above confrontation, and seemed to calm down a little. Honestly, I think I can kind of understand how she felt. Here she was trying to make her way in work that's important, difficult, gets very little recognition for its value, and is traditionally dominated by women, and here comes a man into her world, being asked to speak about it to her and others as if I was doing something new and amazing. Thinking about it in that manner helped keep me humble, and to not take her anger as a personal attack. I would be irritated as well, in her position. If I'm really an ally to her and to the work, as I believe I am, I will do everything in my power to help bring recognition to it and to other women like her, which I've been trying to do. That too is something I must be intentional about if I'm to uphold the steep legacy of birth work, especially in the African American community.

When I first got involved in Public Health, did I ever see myself where I am now? Absolutely not. But I tell you what, I wouldn't change it for the world. The work I do, the support I get from colleagues and leadership, is tremendous. Every bit of success that I've had professionally in the last few years, including a community award and a national award from the de Beaumont Foundation as one of the 40 most innovative professionals in Public Health under 40 years old, is a testament to the support that I've gotten. Yes, I worked hard; yes, I love my work and find passion in it. But as I outlined above, the obstacles and emotional stress that I face as an African American male in this world and in this work are much easier to face when you have people who genuinely care and support you, giving me one less thing to worry about. I love being a trail blazer in birth work. I intend to continue my work as a doula and drive it further. I want to bring innovation to the field in any way possible. Hopefully when all is said and done, diversity in health care and birth work won't be an issue or talking point because it will be more inclusive, properly reflecting all whom we serve. Until then, I will do my part to bring light to it and make sure that I can be a part of the change.

\section{REFERENCES}

Centers for Disease Control and Prevention. (2019). Breastfeeding facts. Retrieved from https:/ / www.cdc.gov/bre astfeeding/data/facts.html

Garcia-Navarro, L. (2018). Black babies twice as likely as white babies to die before age 1 (Weekend ed.). National Public Radio. Retrieved from https://www.npr.org/2018/07 /08/627024896/black-babies-twice-as-likely-as-whitebabies-to-die-before-age-1

Martin, N., \& Montagne, R. (2017). Black mothers keep dying after giving birth. Shalon Irving's story explains why. All things considered. National Public Radio. Retrieved from https:/ / www.npr.org/2017/12/07/568948782/blackmothers-keep-dying-after-giving-birth-shalon-irvingsstory-explains-why

Minnesota Department of Health. (2018). Eliminating health disparities initiative: Infant mortality grants fiscal years 2015 to 2017. Retrieved from https:/ / www.health.state .mn.us/communities/equity/reports/infantmortality 2018.pdf

Disclosure. The author(s) have no relevant financial interest or affiliations with any commercial interests related to the subjects discussed within this article.

Funding. The author(s) received no specific grant or financial support for the research, authorship, and/or publication of this article.

Correspondence regarding this article should be directed to William Moore at wrmoore.cpe.consult@gmail.com

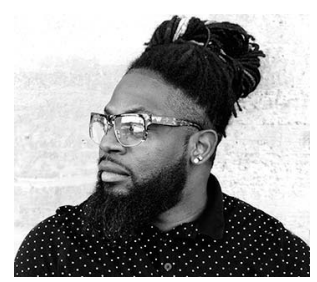

William Moore, CPE (he/him/his), is a health educator and certified perinatal educator at St. Paul Ramsey County Public Health, and one of the first two men in the history of the state of Minnesota to be a certified doula and lactation educator. 